\title{
Estudo Comparativo da Presença dos Fatores Prognósticos Receptor de Estrogênio, cerbb-2, p53 e e-caderina no Câncer Primário da Mama e sua Recidiva Local
}

Autor: José Luiz Pedrini

Orientador: Prof. Dr. Cláudio Galleano Zettler

Dissertação de Mestrado apresentada ao Programa de Pós-Graduação em Patologia: Patologia Experimental da Fundação Faculdade Federal de Ciências Médicas de Porto Alegre e da Irmandade da Santa Casa de Misericórdia de Porto Alegre em 20 de dezembro de 2001

A recidiva local (RL) do câncer de mama varia de 4 a $20 \%$ em 10 anos e pode representar um mau prognóstico da doença. Noventa por cento dos casos surgem nos primeiros 5 anos. Novos marcadores tumorais estão sendo estudados para se estabelecer sua validade clínica como fatores de prognóstico e preditivos para a RL. O objetivo deste trabalho foi comparar a expressão de quatro marcadores tumorais (Receptor de Estrogênio-RE, cerbB2, p53 e E-caderina) no tumor primário de mama (TU) e na sua correspondente RL. Foram estudados 57 casos de câncer de mama recidivados que, após serem revisados, foram estudados por imuno-histoquímica. Não houve diferença significativa entre as variações das expressões positivas e negativas no TU e na RL, na expressão do c-erb-B2 $($ Kappa $=0,86)$, da E-caderina $($ Kappa $=0,55)$ e do p53
(Kappa=0.7). Entretanto, os RE apresentaram um indice Kappa baixo (Kappa=0.26, p>0.05). Estes dados sugerem que a expressão do p53, E-caderina e cerbB2 não se modifica na RL. Todavia, a expressão do RE deve ser reavaliada, pois houve modificação importante na RL (dos TU negativos para RE, 44\% tornaram-se positivos na RL). Por ter valor preditivo, o RE deverá ser sempre reavaliado no reaparecimento do câncer da mama, originando um importante questionamento: o uso profilático de bloqueador estrogênico (tamoxifeno, p.ex), em TU com RE negativo na prevenção da RL que pode ter expressão positiva (44\% dos casos).

Palavras-chave: Mama: câncer. Câncer: recorrência. Marcadores tumorais. Prognóstico.

\section{Repercussões Maternas e Perinatais do Exercício Aquático Terapêutico (Hidroterapia) na Gestação}

Autora: Tânia Terezinha Scudeller Prevedel

Orientadora: Profa. Dra. Iracema de Mattos Paranhos Calderon

Dissertação de Mestrado apresentada ao Curso de Pós-Graduação em Ginecologia e Obstetrícia; Área de concentração: Obstetrícia, da Faculdade de Medicina de Botucatu/SP - Unesp, em 28 de fevereiro de 2002.

Objetivo: Estudar os efeitos maternos (composição corporal e capacidade cardiovascular) e perinatais (peso e prematuridade) da prática da hidroterapia na gestação. Sujeitos e método: Estudo prospectivo, tipo coorte, aleatorizado, com 41 gestantes de baixo risco e gestação única. Aplicou-se programa de hidroterapia da $16^{\mathrm{a}}-20^{\mathrm{a}}$ até a $38^{\mathrm{a}}$ semana de gestação com freqüência de três vezes por semana e duração de uma hora (grupo Estudo, $n=22)$. O Controle foi constituído por 19 gestantes nãopraticantes de hidroterapia. Avaliações antropométricas no início e final do programa, definiram os índices de peso corporal, massa magra e gordura absoluta e relativa, pré e pós-hidroterapia. Por teste ergométrico, definiram-se os índices iniciais e finais de consumo máximo de oxigênio ( $\mathrm{VO}_{2}$ máx), volume sistólico (VS) e débito cardíaco (DC). Como resultado perinatal observou-se ocorrência de prematuridade e baixo peso.

Resultados: A comparação entre os grupos não eviden- ciou diferença significativa nas variáveis maternas no início e no final do programa de hidroterapia. A comparação dentro de cada grupo confirmou efeito benéfico da hidroterapia: - no Estudo os índices de gordura relativa foram mantidos $(29.0 \%)$ e no Controle aumentaram de 28.8 para $30.7 \%$. O grupo Estudo manteve os indices de $\mathrm{VO}_{2}$ máx (35.0\%) e aumentou VS (106.6 para 121.5) e DC (13.5 para 15.1); no Controle observou-se queda nos índices de $\mathrm{VO}_{2}$ máx e manutenção de VS e de DC. A hidroterapia não se relacionou aos resultados perinatais.

Conclusões: A hidroterapia favoreceu adequada adaptação metabólica e cardiovascular maternas à gestação e não determinou prematuridade e baixo peso nos recém-nascidos.

Palavras-chave: Gravidez normal. Hidroterapia. Composição corporal. Capacidade cardiovascular. 